\title{
Comparison Between Conventional and Digital Essay Writing Assessment System: Consumer Concept and User Friendly
}

\author{
Adenan $\mathrm{Ayob}^{1}$ \\ ${ }^{1}$ Sultan Idris Education University, Perak, Malaysia \\ Correspondence: Adenan Ayob, Sultan Idris Education University, Perak, Malaysia.
}

Received: May 1, 2019

Accepted: June 1, 2019

Online Published: July 9, 2019

doi:10.5430/rwe.v10n2p96

URL: https://doi.org/10.5430/rwe.v10n2p96

\begin{abstract}
Significant changes occurred in education system; teaching and learning technology in this new era. The changes can be revised through the existence of digital assessment system for essay writing. In utilizing and interpreting these changes, this study was conducted to examine the use of digital and conventional assessment system for Form Three among Malay teachers. The survey method was used in this study. The samples of the study are 60 teachers of the national secondary school which taught Malay Language for form three in Selangor and Federal Territory of Kuala Lumpur. The data are described descriptively and inferentially. Descriptive data are mean and standard deviation. Inferential data was analyzed using ANCOVA statistics. The findings show that there is a significant difference in teachers' opinion on the use of digital assessment system and the use of conventional assessment materials that based on consumer concept and user friendly. From that perspective, digital scoring system make teachers more dynamic in scoring the essay writing for form three. Therefore, it is recommended to the Ministry of Education to implement and revise the use of digital assessment system to improve the process for primary and secondary schools.
\end{abstract}

Keywords: teaching and learning technology, conventional and digital assessment system, consumer concept, user friendly

\section{Introduction}

Several studies showed the use of computers and certain system for evaluation process. Specific studies were conducted by Norabeerah, Halimah and Azlina (2011) who have investigated the use of computers for writing assessment. They focused on the effectiveness of computer and specialized system for getting writing scores. In the meantime, there are some problems that indicate the use of conventional system involving assessment. Parveen and Rajesh (2011) in his study find out about the using of conventional assessment was ineffective because it is not systematic, consumer concept and user friendly, as well as requiring a significant amount of time. In addition, there are problems in terms of structural and hypertext references in assessment criteria through the effectiveness regarding administration and management of scoring (Rosidah Awang Besar, 2013). In addressing these issues, the assessment study by using computer as a dynamic tool in specific study need to be implemented.

\section{Computer for Assessment}

Consequently, the use of computers to digitalize assessment in the process of evaluation of the Malay language is seen to be an appropriate step in order to provide the impact on settlement of all relevant issues or current issues encountered. As a systematic assessment tool and easy to access and up-to-date (Adenan Ayob, 2018), the use of computer-based digital syetem is seen as a vehicle capable of boosting innovation in the secondary school assessment process (Adenan Ayob et al., 2010; Fullan, 2011; Khan, Hassan \& Marimuthu 2017). In fact, the use of digital assessment system in the context of pedagogy and should be a starting point for various research findings (Yusalina Yusof, 2011; Hsiao, et al. 2017). According to Rosnaini Mahmud, Mohd Arif Ismail and Jalalludin Ibrahim (2011), if any educational system needs to be built and used, a thorough study should be done, firstly to identify their validity and reliability. Therefore, this study attempts to review teachers' opinions on using digital assessment system for essay writing. This study was conducted in two states, namely Selangor and Federal Territory of Kuala Lumpur. 


\section{Research Objective}

i. Review teacher's opinion on using form three digital and conventional assessment system for essay writing in both states.

ii. Comparing teacher's opinions between digital and conventional assessment system for essay writing in both states.

\section{Research Question}

i. What is the teacher's opinion on using form three digital and conventional assessment system for essay writing in both states?

ii. Is there any significant between digital and conventional assessment system for essay writing in both states?

\section{Operational Definition}

\subsection{Consumer Concept}

There are many interpretations about consumer concept. Adenan Ayob (2018) defines consumer concept as a vehicle and measurement in terms of the use and delivery of digital materials that involves teachers and students actively and enables feedback. According to him, the computer can be used as a teaching and learning medium because it has the privilege of access or access such as assessment.

\subsection{User Friendly}

The user-friendly aspect when computer hardware and software are used to be interpreted and measured. User friendly means medium and measurement via easy access. Smoothly accessing is for navigation and storage (Mayer, 2003; Hassan \& Kommers 2018). According to him, the time used is fast, more links and scanning and data are analyzed automatically.

\section{Previous Studies}

Some previous studies have been highlighted. In the first review, Rudner and Gagne (2001) studied teacher's satisfaction using computer for assessment. His study involves 100 secondary school teachers. The survey method is based on closed questionnaire. There are a few items that touch on consumer concept and user friendly. The data were analyzed descriptively. The results showed that $85 \%$ of teachers have satisfaction in using computer for assessment. The results of this study also showed that computer is suitable for language assessments.

The next past study observed teacher from the activeness angle and time spent for essay assessment based on computer. Study done by Lee (2007) in one of the high schools in Hong Kong using observation method has been done successfully. The data were collected based checklist. The descriptive data obtained indicate that all teachers are very active. Twenty teachers need a relatively exact time, about 30 minutes to provide assessment input. The remaining 10 teachers took 10 to 15 minutes long.

The two above studies did not highlight the use of specialized systems in language assessment. Both studies only relate to the use of normal program. It is firmly showed that the studies did not use the assessment tools that specifically developed for essay writing. The tools of both studies are not in the context of the .html and databases (Haseeb, et al. 2018).

\section{Methodology}

\subsection{Research Methods}

This study was carried out in descriptive and inferential using survey method. A total of 60 Malay teachers were used as a sample. The samples involved teachers in several schools in Selangor and Federal Territory of Kuala Lumpur. Two schools were selected for this study. Permission from the school was obtained for research implementation.

\subsection{The Characteristics of Sample}

Sixty experienced male and female teachers were selected as sample. They were 60 teachers in Federal Territory of Kuala Lumpur and Selangor. The teaching experience is eight years. For each school, 30 teachers were selected based on simple random sampling techniques. According to Gay and Gay (1985), sample selection can be done based on the probability of survey, as well as involving a stream of instructors. Therefore, justification for the selection of this sample has been adjusted to his view. 


\subsection{Instrument}

For data collection, two set of questionnaires were used. In each questionnaire there are 30 items that based on two dimensions, respectively for digital and conventional assessment system; Consumer Concept is 15 items and User Friendly is also 15 items. Please refer to the following table:

\begin{tabular}{lll}
\hline \multirow{2}{*}{ Dimension } & Quantity of Item & Total Item \\
& & \\
\hline Consumer Concept & 15 & 30 \\
\cline { 2 - 3 } & 15 & 30 \\
\hline User Friendly & 15 & 30 \\
\hline
\end{tabular}

The Likert Scale is used, that is 4 to Strongly Agree; 3 to Agree; 2 to Disagree; and 1 to Strongly Disagree. For this study, the questionnaire was adapted from Marwan and Sweeney (2010). According to Gay and Gay (1985), a modified questionnaire can be accepted as a standard instrument.

\subsection{Data Analysis}

Data analysis is based on two research questions. Data analysis is shown in Table 1.

Table 1. Data analysis

No.

Research Question

Analysis

1. What is the teacher's opinion on using form three digital Descriptive: and conventional assessment system for essay writing in Min dan Standard both states?

Deviation

2. Is there any significant between digital and conventional Inferential: assessment system for essay writing in both states?

ANCOVA

\section{Findings}

i. What is the teacher's opinion on using form three digital and conventional assessment system for essay writing in both states?

The next table describes the mean and standard deviation of the teacher's opinion on the use of digital scoring materials and conventional scoring materials for the writing of the three factual essay assessments analyzed for a primary school in the Federal Territory of Kuala Lumpur. Min and standard deviation are presented in Table 2.

Table 2. Mean and standard deviation of teachers' opinion in the Federal Territory of Kuala Lumpur

\begin{tabular}{lll}
\hline Assessment & Mean & SD \\
\hline Conventional & 61.0 & 10.1 \\
Digital & 83.7 & 7.3 \\
\hline
\end{tabular}


From Table 2, mean teachers' opinion on using of conventional assessment system for the Federal Territory of Kuala Lumpur is 61.0 ( $\mathrm{SP}=10.1)$. The teacher's opinion on using digital system is 83.7 ( $\mathrm{SP}=7.3$ ).

The next table 3 shows the mean and standard deviation of teachers' opinion in Selangor. Min and standard deviations are shown in Table 3.

Table 3. Min and standard deviation of teachers' opinion in Selangor

\begin{tabular}{lll}
\hline Assessment & Mean & SD \\
\hline Conventional & 65.2 & 10.2 \\
Digital & 83.7 & 7.7 \\
\hline & & SD is standard deviation
\end{tabular}

In Table 3, mean teachers' opinion on using conventional assessment system for Selangor is $65.2(\mathrm{SP}=10.2)$. The teacher's opinion on using digital system is $83.7(\mathrm{SP}=7.7)$.

ii. Is there any significant between digital and conventional assessment system for essay writing in both states?

Table 4 presents covariance analysis. The analysis is for Federal Territory of Kuala Lumpur.

Table 4. Covariance analysis of teacher's opinion for Federal Territory of Kuala Lumpur

\begin{tabular}{llllll}
\hline Assessment & $\begin{array}{l}\text { Total } \\
\text { Squared }\end{array}$ & df & $\begin{array}{l}\text { Mean } \\
\text { Squared }\end{array}$ & F & Sig. \\
\hline Conventional & 2215.43 & 1 & 171.81 & 173.3 & 0.000 \\
Digital & 177.56 & 1 & 12.15 & 13.3 & 0.002 \\
Error & 342.08 & 27 & & & \\
Total & 168014 & 30 & & & \\
Corrected & & & & & \\
Total & 5433.85 & 29 & & & \\
\hline
\end{tabular}

Significant Level $<0.05$

Table 4 shows the value of $F(1,27)=13.3$, with a significant level of $<0.05$. This shows that there is a significant difference in the opinion of teachers in Selangor between conventional and digital assessment system, when opinions on using conventional assessment system are variance.

Table 5 also presents covariance analysis. The analysis is for Selangor.

Table 5. Covariance analysis of teachers' opinions for Selangor

\begin{tabular}{llllll}
\hline Assessment & Total & df & $\begin{array}{l}\text { Mean } \\
\text { Squared }\end{array}$ & F & Sig. \\
\hline Conventional & 2489.43 & 1 & 205.4 & 174.9 & 0.000 \\
Digital & 76.7 & 1 & 77.73 & 6.9 & 0.001 \\
Error & 315.83 & 27 & & & \\
Total & 173412 & 30 & & & \\
Corrected & & & & & \\
Total & 5135 & 29 & & & \\
\hline
\end{tabular}

Significant Level $<0.05$ 
Table 5 shows the value of $F(1,27)=6.9$, with a significant level of $<0.05$. This shows that there is a significant difference in the opinion of teachers in Selangor between conventional and digital assessment system, when opinions on using conventional assessment system are variance.

\section{Discussion}

The significant findings of this study in both states support Marwan and Sweeney (2010) study that on both dimensions of using digital assessment system can affect the quality of scoring. This is because the teacher's opinion should be taken into account in using technological assessment system in education. The using of digital assessment system are focused on consumer concept and user friendly, and should be prioritized (Norabeerah, Halimah \& Azlina, 2011; Hassan \& Alanazi 2018).

In Norabeerah, Halimah and Azlina (2011) study too, teacher's opinion on using digital assessment system in education has high impact in terms of consumer concept and user friendly. Parveen and Rajesh's finding (2011) also provide teacher's opinion criteria on using digital assessment system has to be aligned with both dimensions on the impact on user friendly, and to be implemented smoothly.

The using of digital assessment system in education, particularly in the evaluation process of interactive multimedia aspects, that is texts and hypertext that contributes to systematically assessing scoring (Mayer, 2003; Adenan Ayob et al., 2010). The arrangement in non-linear or interactive multimedia organizations through digital materials facilitates the editing of assessment by teachers (Rosnaini Mahmud, Mohd Arif Ismail \& Jalalludin Ibrahim, 2011).

The findings from Parveen and Rajesh (2011) show that the using of digital assessment system in education that involves online criteria can attract teachers. Computer-assisted assessments cover the aspects of testing, measurement, and dynamic assessment, in addition to time required for teacher's preparation, as well as accessible online (Norabeerah, Halimah \& Azlina, 2011).

In fact, education has been a challenging time, especially in terms of using assessment tools, either by teacher or student. Hence, the using of computer-based digital assessment system in evaluation process improves teacher's ability in transforming their digitization especially in information technology (Adenan Ayob et al., 2010). Therefore, the aspect of infrastructure in using digital assessment system that based on certain interactive multimedia elements can stimulate internet applications in educational management by guiding the teacher's basic needs.

\section{Conclusion}

As a matter of fact, this study impacted the extent of computer research as a vehicle to transmit evaluation processes that are specific to the scoring aspects. Technology-based assessment system should be focused to teacher's opinion before being tried and practiced. This assessment system is an educational innovation to avoid manual practices. Obviously, the innovations of assessment, testing and measurement need to be revised scientifically and instructionally to empower and transform modern education.

\section{Acknowledgement}

The acknowledgement is directed to the Research Management and Innovation Centre, Sultan Idris Education University that offer a special grant in 2016 (code 2016-0113-107-01) for allowing this study to be conducted. This grant is important to propel research knowledge for technological education.

\section{References}

Ayob, A. (2018, June). Pedagogy and Multimedia Integration System Model for Writing. Int. J. Manag. Bus. Res., $8(2), 181-188$.

Ayob, A. et al. (2010). Multimedia in teaching Malay Language. Emeritus Publications: Tanjung Malim.

Fullan, M. (2011). The new meaning of educational change (3rd ed.). New York, New York Teacher College Press.

Gay, L. R., \& Gay, L. R. (1985). Educational evaluation and measurement: Competencies for analysis and application. Columbus: C. E. Merrill Pub. Co.

Haseeb, M., Abidin, I. S. Z., Hye, Q. M. A., \& Hartani, N. H. (2018). The impact of renewable energy on economic well-being of Malaysia: Fresh evidence from auto regressive distributed lag bound testing approach. International Journal of Energy Economics and Policy, 9(1), 269-275.

Hassan, H. S., \& Alanazi, T. M. (2018). Roles of Islamic Business Ethics in the Formation of Internal Organisational Culture: A Qualitative Approach of Muslims' SMEs in the UK. International Journal of Economics, Business and Management Studies, 5(1), 16-30. https://doi.org/10.20448/802.51.16.30 
Hassan, M. I. A., \& Kommers, P. (2018). A Review on Effect of Social Media on Education in Sudan. International Journal of Educational Technology and Learning, 3(1), 30-34. https://doi.org/10.20448/2003.31.30.34

Hsiao, C. M., Zhang, W. F., Chiu, C. C., Huang, J. C., \& Huang, Y. L. (2017). The Enterprise Risk Management of Foreign Exchange Exposures: Evidence from Taiwanese Hospitality Industry. Asian Journal of Economics and Empirical Research, 4(1), 32-48. https://doi.org/10.20448/journal.501.2017.41.32.48

Khan, H., Hassan, R., \& Marimuthu, M. (2017). Diversity on corporate boards and firm performance: An empirical evidence from Malaysia. American Journal of Social Sciences and Humanities, 2(1), 1-8. https://doi.org/10.20448/801.21.1.8

Lee, I. (2007). Feedback in Secondary Writing Classrooms: Assessment for Learning or Assessment of Learning?. Assessing Writing, 12(3), 180-198. https://doi.org/10.1016/j.asw.2008.02.003

Marwan, A., \& Sweeney, T. (2010). Teachers Perception of Educational Technology Integration in an Indonesian Polytechnic. Asia Pacific Journal of Education, 30(4), 463-476. https://doi.org/10.1080/02188791.2010.519554

Mayer, R. E. (2003). The Promise of Multimedia Learning: Using the Same Instructional Design Methods Across Different Media. Learning and Instruction, 13, 125-139. https://doi.org/10.1016/S0959-4752(02)00016-6

Norabeerah, S., Halimah, B. Z., \& Azlina, A. (2011). Technical skills in developing augmented reality application: Teachers' readiness. In B. Z. Halimah, P. Robinson, M. Petrou, P. Olivier, T. Shih, S. Velastin \& I. Nyström (Eds.), Visual informatics: Sustaining research and innovations (Vol. 7067, pp.360-370). Heidelberg: Springer Verlag Berlin. https://doi.org/10.1007/978-3-642-25200-6_34

Parveen, J. J., \& Rajesh, V. (2011). Multimedia in English Language Teaching: An Empirical Study. Journal of Technology for ELT, 1(4).

Rosidah Awang Besar. (2013). The use of ICT in topics for primary schools. Universiti Utara Malaysia.

Rosnaini Mahmud, Mohd Arif Ismail, \& Jalalludin Ibrahim. (2011). Level of Skill and Integration of ICT in Smart School Teacher. Educational Technology Journal, Malaysia, 1(1), 5-13.

Rudner, L., \& Gagne, P. (2001). Three Approaches in Essay Assessments using Computer. Practical Assessment, Research \& Evaluation, 7(26), 1-6.

Yusalina Yusof. (2011). Implementation of ICT pedagogical innovation in teaching. UKM. 